\title{
Создание и анализ 100-летних рядов солнечной активности
}

\author{
К.А. Тлатова ${ }^{1}$, В.В. Васильева ${ }^{1}$, Н.Н. Скорбеж ${ }^{1}$, А.Г. Тлатов ${ }^{1,2}$ \\ 1 Кисловодская Горная астрономическая станция ГАО РАН \\ k.tlatova@mail.ru \\ 2 КалмГУ, Элиста
}

Поступила в редакцию 16 ноября 2017 г.

Аннотация. Выполнена оцифровка данных, за период более 100 лет, включающая в себя характеристики элементов солнечной активности: солнечных пятен, ядер, волокон, флоккул и протуберанцев. Созданы базы данных векторных границ и фотометрических свойств объектов.

На основе полученных данных были определены характеристики отдельных видов солнечной активности. Создан интерактивный атлас, на котором представлены ежедневные и синоптические карты. Реконструированы индексы солнечной активности и выполнен анализ.

CREATION AND ANALYSIS OF 100-YEAR SERIES OF SOLAR ACTIVITY, by K.A. Tlatova, V.V. Vasil'eva, N.N. Skorbez, A.G. Tlatov. We digitized data covering a period of more than 100 years, consisting of characteristics of individual sunspots, umbrae, filaments, plages, and prominences. Databases of vector boundaries and photometric properties of objects were generated.

Based on the obtained data, the characteristics of individual types of solar activity were determined. Also, an interactive atlas of solar activity was compiled, which presents daily and synoptic maps of solar activity, the characteristics of individual elements, and summary indices of solar activity. The indices of solar activity were reconstructed and the analysis was carried out.

Ключевые слова: Солнце, наблюдения, длительные ряды

\section{1 Введение}

Существует два вида долговременных рядов данных: табличные базы данных и фотографические архивы. Долговременные табличные базы данных доступны за достаточно большой период времени, к примеру, индексы солнечных пятен (числа Вольфа) с 1818, площадь солнечных пятен с 1874 , полярные факелы с 1874, положение солнечных волокон с 1915, характеристики протуберанцев с 1907 и другие (Ермолли и др., 2014). Однако все эти ряды не однородны и имеют ограниченный набор характеристик.

Фотографические архивы, в свою очередь, могут нести намного больше информации, чем табличные данные. С помощью фотографических архивов можно просматривать формы и извлекать площади, длины, положения и другие характеристики элементов солнечной активности. Это является немаловажным фактором, так как раньше, например, при измерении площадей солнечных пятен использовали заготовленные шаблоны (трафареты), что мешало определить реальную площадь. Однако на сегодняшний день существует большее количество долговременных фотографических архивов 
ежедневных изображений Солнца. Некоторыми из них мы воспользовались в своей работе для того, чтобы создать банк данных элементов солнечной активности за период более 100 лет.

База данных включает в себя оцифровку фотографических архивов ежедневных солнечных синоптических наблюдений. В том числе: магнитных полей солнечных пятен по зарисовкам обсерватории Маунт-Вилсон 1917-2016 гг. (рис. 1), солнечных пятен на фотопластинках Гринвичской обсерватории 1919-1972 гг. и Горной астрономической станции (ГАС) 1954-2016 гг. (Тлатов и др., 2016); флоккул в спектральной линии CaIIK за период 1905-2016 гг. по данным обсерваторий Кодайканал, Маунт-Вилсон (MWO), Сакраменто-Пик (SP) и ГАС ГАО (Тлатов и др., 2009); солнечных волокон, наблюдаемых в линии $H_{\alpha}$ за период 1915-2016 гг. по данным обсерваторий Кодайканал (KKL), Meдон, Сакраменто-Пик, Канцельхое и ГАС; протуберанцев, наблюдаемых в линиях $H_{\alpha}$ и CaIIK за период 1910-1944 гг. по данным обсерваторий Кодайканал, ГАС и зарисовок международной наблюдательной сети спектрогелиоскопов.

Целью представленной работы являлось создание базы данных векторных границ и фотометрических свойств элементов солнечной активности по ежедневным данным наблюдений за период около 100 лет. Создание новых индексов, получаемых из топологических свойств на ежедневных изображениях различных обсерваторий, а также предварительный анализ полученных данных.

\section{2 Исходные данные}

В качестве исходных данных мы брали фотографические архивы ежедневных солнечных синоптических наблюдений, перечисленные выше. Для обработки баз данных было разработано программное

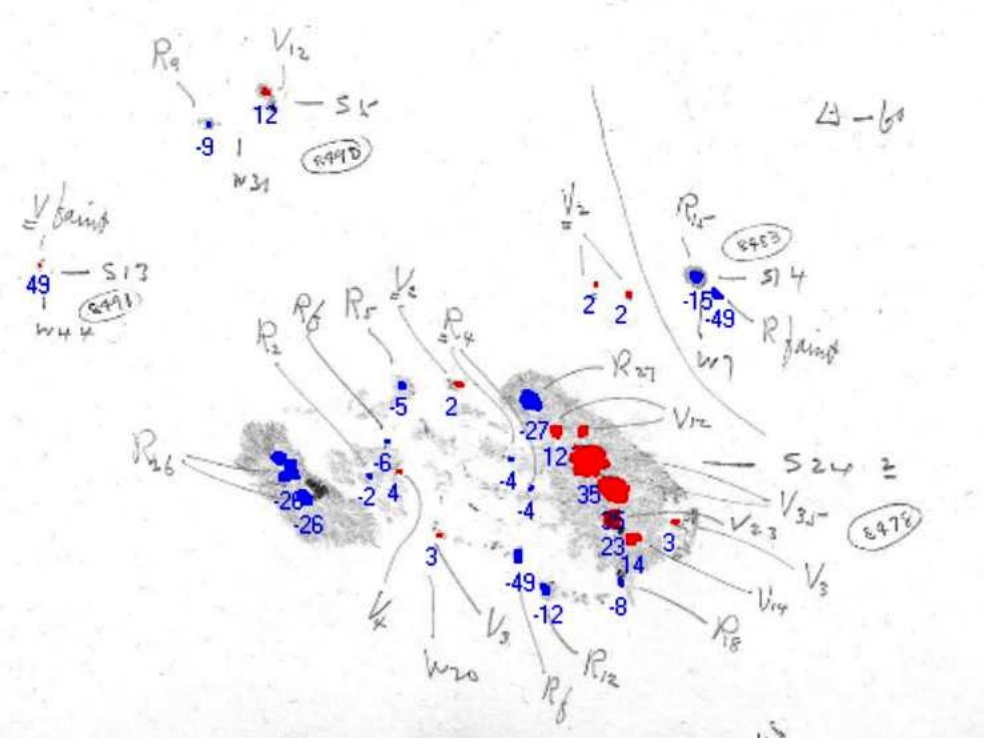

Рис. 1. Пример выделения ядер солнечных пятен и их напряженностей на зарисовках обсерватории МаунтВилсон

обеспечение, при помощи которого для каждого элемента солнечной активности, кроме протуберанцев, мы измеряли гелиографические координаты, площадь в пикселях, площадь в физических единицах, исправленную за гелиографическую проекцию, время наблюдений, в случае магнитных полей солнечных пятен - напряженность магнитного поля и другие. На рис. 1 представлен пример выделения ядер солнечных пятен и их напряженностей по зарисовкам MWO. 
Данные международной наблюдательной сети спектрогелиоскопов представляют собой развертки вдоль лимба за каждый день с зарисовками протуберанцев. По пороговому уровню яркости программа автоматически находила протуберанцы и выделяла их контуры, которые в дальнейшем корректировались и запоминались в векторном формате. После завершения редактирования дня создавалась круглая карта с уже выделенными ранее протуберанцами за текущий день. Таким образом, всего в период 1922-1934 гг. было выделено 51866 протуберанцев для 4708 наблюдательных дней (Тлатова, Нагнибеда, 2017).

Общее количество дней (из числа обработанных нами наблюдений) для данных магнитных полей солнечных пятен по зарисовкам обсерватории Маунт-Вилсон в период 1917 г. по октябрь 2016 г. составило 20318 (Тлатова и др., 2015). Число измерений магнитного поля отдельных ядер и пор составило 441973.

Количество солнечных волокон, наблюдаемых в линии $H_{\alpha}$ за период 1915-2002 гг. по данным обсерватории Кодайканал, составило 326236 волокон на 24308 изображениях. По данным обсерватории Медон в период 1980-2015 гг. было выделено 145500 волокон на 8270 изображениях. Количество солнечных волокон в линии $H_{\alpha}$, наблюдаемых в обсерватории Сакраменто Пик в период 1964-2002 гг., составило 46800 волокон на 4992 изображениях (Тлатова и др., 2017).

\section{3 Результаты}

Полученная база данных характеристик элементов солнечной активности позволяет построить ежедневные сводные карты, пример представлен на рис. 2. Еще одним значимым результатом на основе новой базы данных является создание сводных синоптических карт (рис. 3). Таким образом, мы

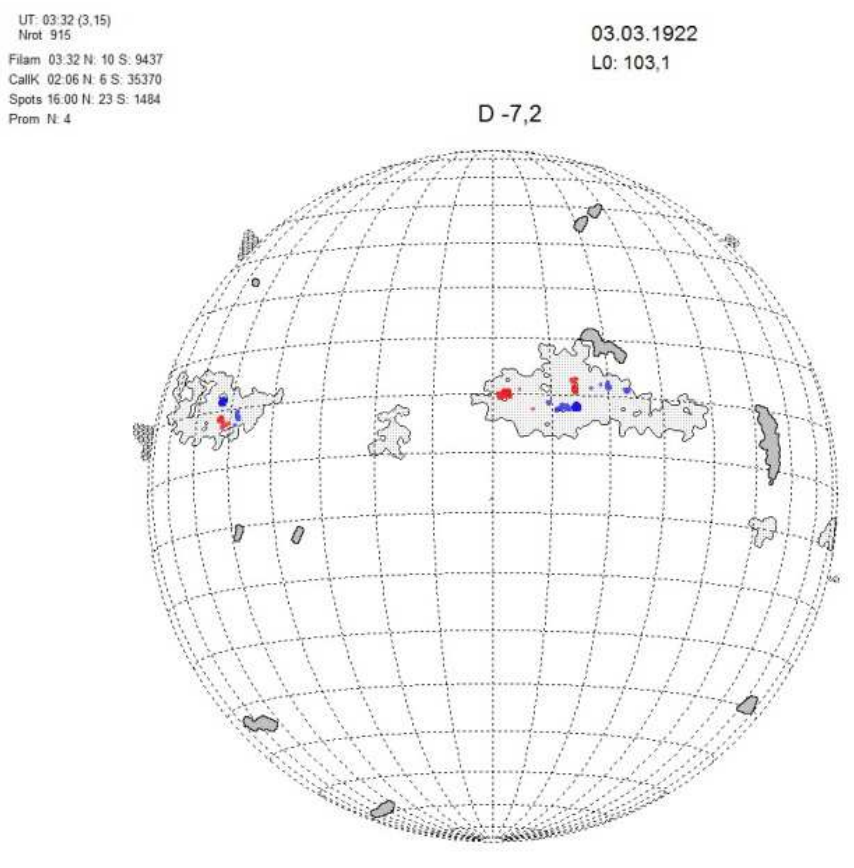

Рис. 2. Пример сводной карты за 03.03.1922 г.

можем воссоздать общую картину активности Солнца за столетний период. Еще одним немаловажным пунктом нашей работы являлось создание интернет-ресурса, на котором была бы представлена визуализация современных и исторических данных солнечных наблюдений на основе построенных 


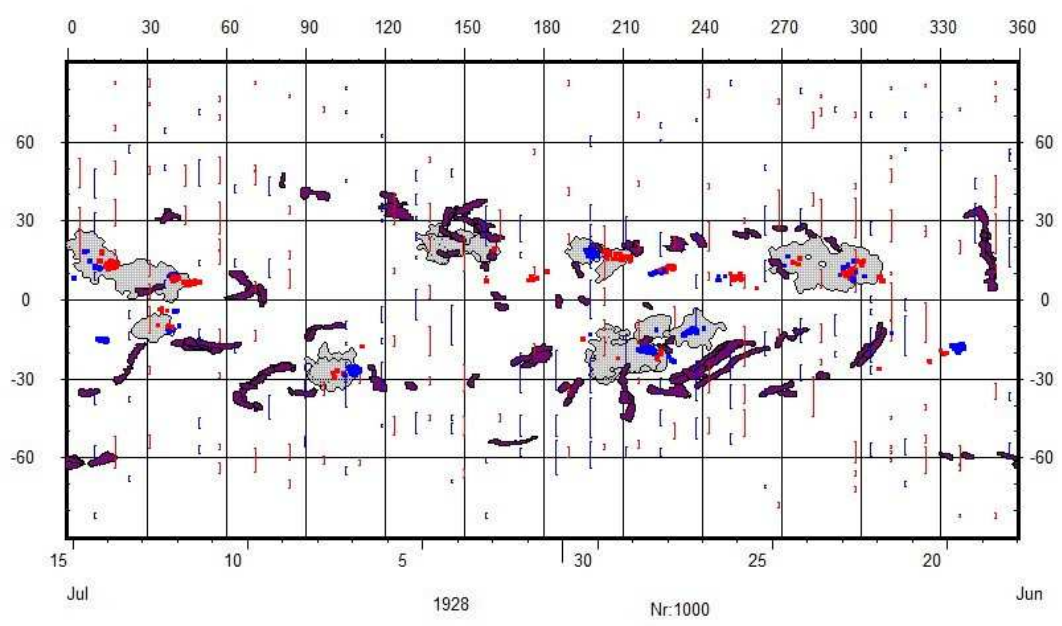

Рис. 3. Пример сводной синоптической карты кэррингтоновского оборота N 1000

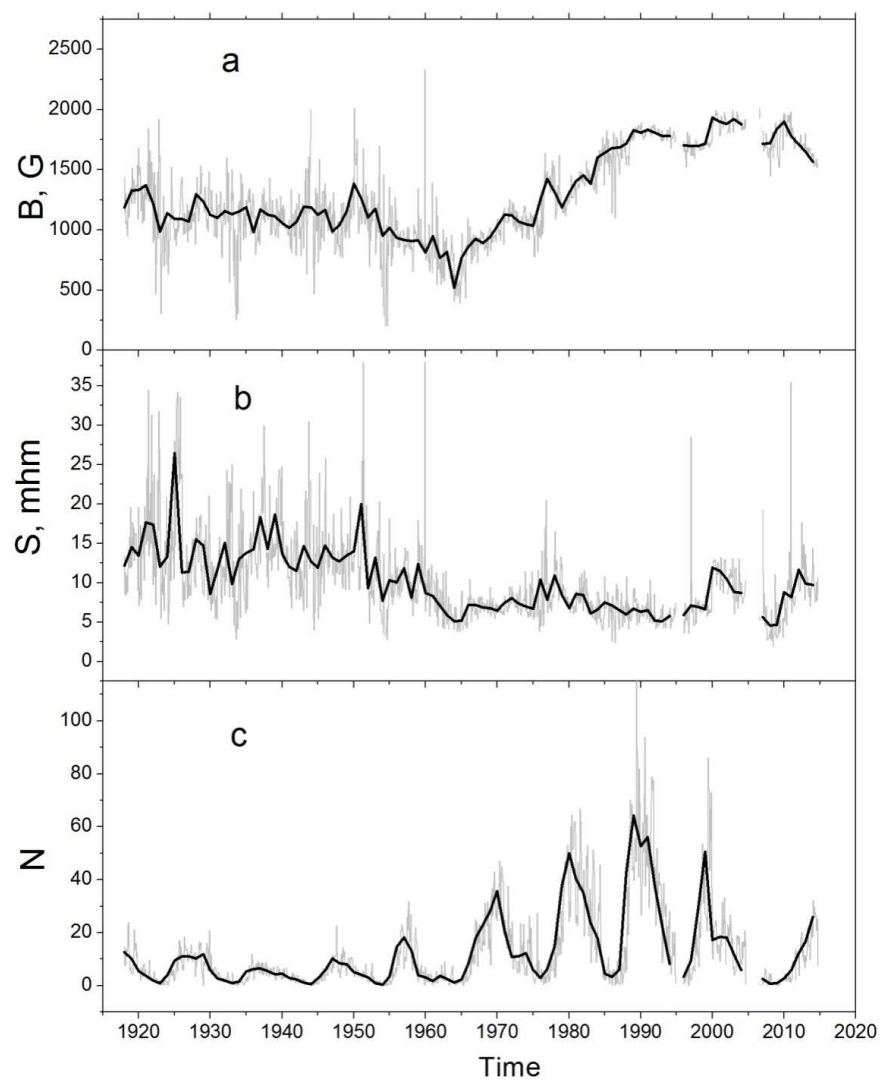

Рис. 4. Среднемесячные (серый цвет) и среднегодовые (черная толстая линия) значения по данным наблюдений обсерватории Маунт-Вилсон: a) напряженности магнитных полей солнечных пятен $B$ в гауссах; b) средней площади измеряемых пятен и пор в единицах $10^{-6}$ солнечной полусферы; с) количество измерений в день 
сводных карт солнечной активности. Такой интернет-ресурс был создан и в настоящее время является общедоступным ${ }^{1}$ (Илларионов, Тлатов, 2017). На сайте представлена трехмерная модель Солнца с его видимой частью и темной стороной, на которой нанесены реальные размеры и положения таких элементов солнечной активности, как флоккулы и волокна, протуберанцы, ядра и полутени солнечных пятен, а также корона и корональные дыры. Существует возможность просмотра номера оборота, числа Вольфа и площади пятен за текущий день, гелиографические координаты курсора и положение центрального меридиана и экватора. При выборе определенного объекта отображаются его параметры, такие как площадь, долгота, широта и другие. Еще одной немаловажной функцией является сравнение объектов. Например, можно взять один и тот же объект за несколько дней и сравнить его параметры.

Имея такую обширную базу данных, становится возможным выполнять всесторонний анализ солнечной активности на различных широтах солнечной атмосферы. Так, например, для солнечных пятен можно получать статистические зависимости (рис. 4). В период приблизительно с 1980 г. в данных измерений магнитного поля можно наблюдать исчезновение пятен с небольшими напряженностями (до 1000 Гс), а также пятен с напряженностями свыше 3000 Гс (рис. 4) (Тлатов и др., 2015).

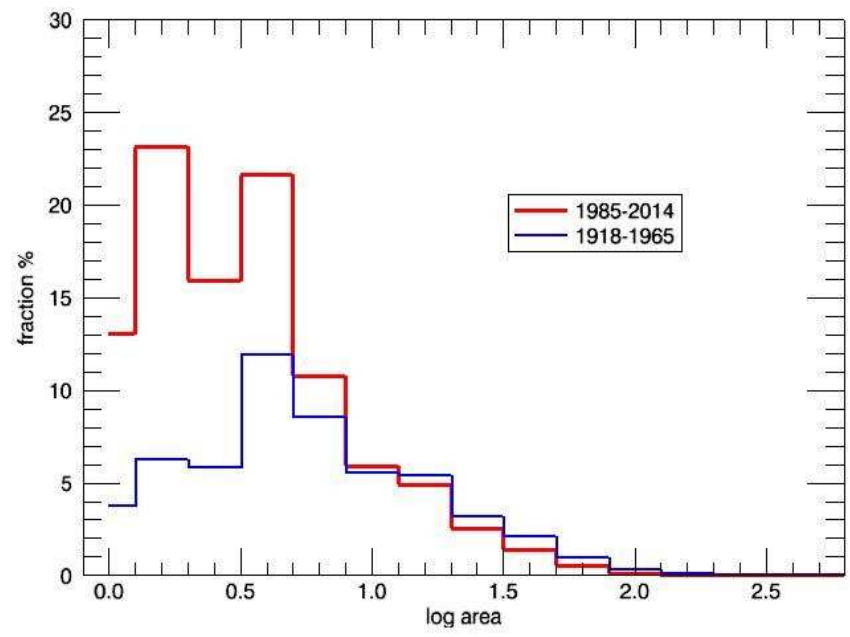

Рис. 5. Гистограмма распределения логарифма площади измеряемых ядер пятен и пор измерений в период 1918-1965 гг. и 1985-2015 гг.

Ранее в работе (Дмитриева и др., 1968) был найден двухвершинный характер распределения площади солнечных пятен. Знание свойств отдельных солнечных пятен позволяет уточнить это свойство. Распределение относительного количества пятен в зависимости от площади представлено на рис. 5. Изменения площади с 1965 г. по данным MWO показывают, что распределение площади имеет двухвершинный характер (рис. 5). Такой же результат был получен и по данным RGO. Максимум распределения площади наибольшего ядра в группе солнечных пятен, ассоциируемого с магнитной полярностью, соответствующей ведущей полярности приходится на площадь $S_{u m} \sim 25$ мдп. Для остальных ядер в группе число пятен монотонно уменьшается с ростом площади.

${ }^{1}$ http: //www. observethesun.com 


\section{4 Выводы}

Нами была создана уникальная база данных форм различных элементов солнечной активности: пятен, ядер солнечных пятен, волокон, флоккул, протуберанцев, корональных дыр и др. На основе этой базы данных были созданы ежедневные сводные карты солнечной активности за период более 100 лет. Для визуализации современных и исторических данных солнечных наблюдений был разработан уникальный интернет-ресурс www.observethesun.com. Мы получили первые сводные синоптические карты трассеров активности, в дальнейшем планируется уточнение синоптических карт раздела полярности крупномасштабного магнитного поля.

Мы планируем выполнить реконструкцию магнитных полей Солнца и гелиосферы в 11-летнем и 100-летнем циклах активности. Предполагается детально изучить циклы активности в полярных областях Солнца, воссоздать области с открытыми конфигурациями магнитных полей Солнца и на их основе реконструировать параметры солнечного ветра и гелиосферы.

Работа выполнена при частичной поддержке проекта РФФИ №18-02-00098 и проекта РНФ №15$12-20001$.

\section{Литература}

Дмитриева и др. (Dmitrieva M.G., Kopecky M., Kuklin G.V.) // Structure and Development of Solar Active Regions. IAU Symp. N. 35 / Ed. Kiepenheuer K. Dordrecht: D. Reidel Publ. Company. 1968. P. 174.

Ермолли и др. (Ermolli I., Shibasaki K., Tlatov A., van Driel-Gesztelyi L.) // Space Sci. Rev. 2014. V. 186. P. 105.

Илларионов Е.А., Тлатов А.Г. // Изв. Крымск. Астрофиз. Обсерв. 2018. Т. 114. № 1. С. 118.

Тлатов и др. (Tlatov A.G., Pevtsov A.A., Singh J.) // Solar Phys. 2009. V. 255. Issue 2. P. 239.

Тлатов и др. (Tlatov A.G., Skorbehz N.N., Ershov V.) // Astron. Soc. Pacific Conf. Ser. 2016. V. 504. P. 237.

Тлатов и др. (Tlatov A.G., Tlatova K.A., Vasil'eva V.V., Pevtsov A.A., Mursula K.) // Adv. Space Res. 2015. V. 55. Issue 3. P. 835.

Тлатова и др. (Tlatova K.A., Vasil'eva V.V., Pevtsov A.A.) // Geomagn. Aeron. 2015. V. 55. P. 896.

Тлатова, Нагнибеда (Tlatova K.A., Nagnibeda V.G.) // Geomagn. Aeron. 2017. V. 57. P. 829.

Тлатова и др. (Tlatova K.A., Vasil'eva V.V., Tlatov A.G.) // Geomagn. Aeron. 2017. V. 57. P. 825. 